Family Profile No. 9, 2021

\title{
First Marriage Rate in the U.S., 2019
}

Author: Leslie Reynolds

The overall marriage rate (the number of marriages per 1,000 unmarried women aged 15 and older) in the United States began to decline in 1970 but has remained stable since 2010 (FP-19-22). In 2019, the overall marriage rate was 30.5 marriages per 1,000 unmarried women (FP-20-24). The overall marriage rate includes both first and higher order marriages. Since about one-quarter (27\%) of marriages are remarriages (FP-19-14), it is important to examine trends in first marriages separately. This family profile updates past profiles on the first marriage rate using recent data (FP-20-01, FP-18-14, FP-16-18, FP-14-08, FP-11-12, and FP-10-05).

Trends in the First Marriage Rate

- The first marriage rate declined from 49.8 first marriages per 1,000 never married women in 2008 to 43.4 in 2019.

- After reaching a low of 43.1 in 2013 , the marriage rate increased to 45.3 in 2014 and remained stable through 2017.

- Both 2018 and 2019 marriage rates exhibited declines from the prior year.

- An estimated $1,648,830$ women entered a first marriage in 2019.

Figure 1. First Marriage Rate for Never-Married Women 18 and Older, 2008-2019

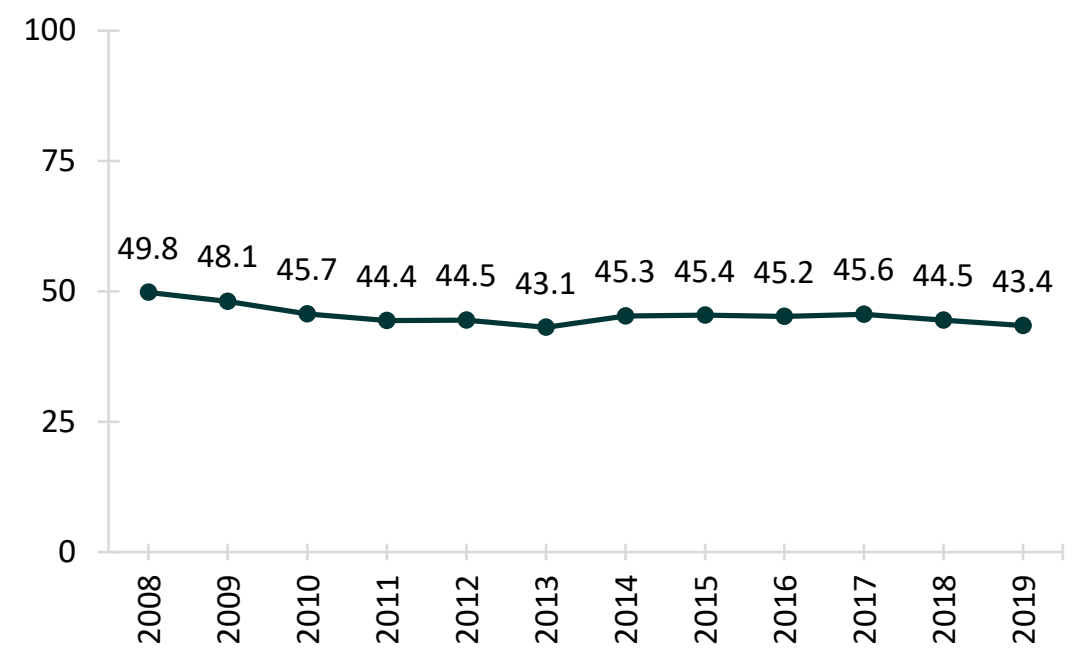

Source: NCFMR analyses of U.S. Census Bureau, American Community Survey, 1-yr. est., 2018-2019
First Marriage Rate by Race and Ethnicity Figure 2. First Marriage Rate for Never-Married Women 18 and Older by Race and Ethnicity, 2019

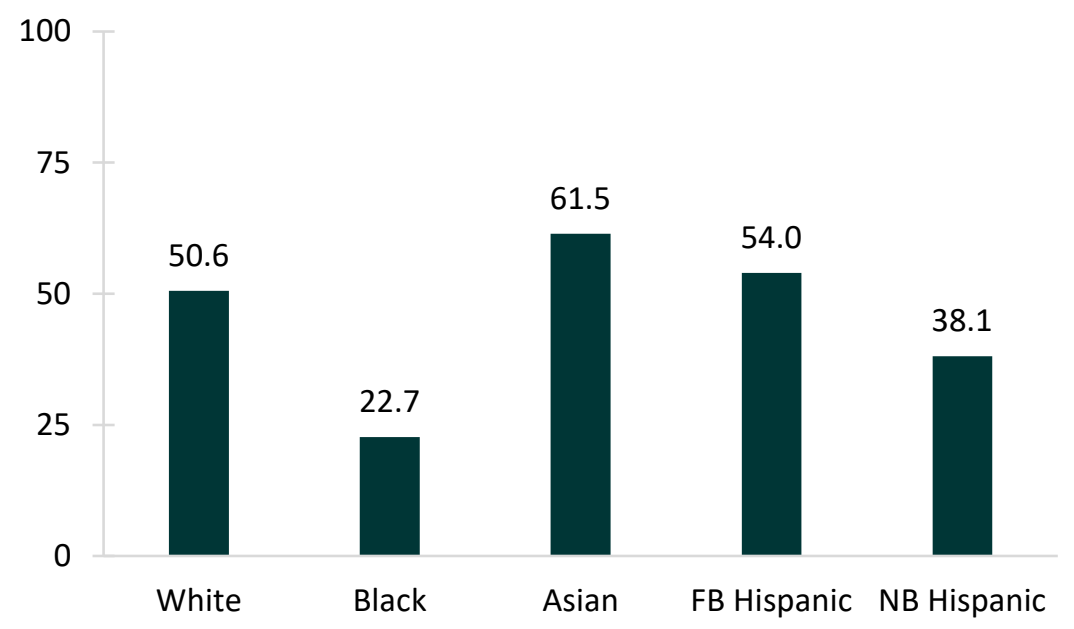

Source: NCFMR analyses of U.S. Census Bureau, American Community Survey, 1-yr. est., 2018-2019
- In 2019, the first marriage rate was highest among Asian women (61.5).

- Black women experienced the lowest first marriage rate (22.7) of the racial/ethnic groups examined.

- Among Hispanics, those who were foreign-born had a higher first marriage rate (54.0) than Hispanics born in the U.S. (38.1). 


\section{First Marriage Rate by Educational Attainment}

- Women with a two-year college degree or more had substantially higher first marriage rates than women without college degrees.

○ The first marriage rate was 50.5 per 1,000 never-married women among those with an associate's degree, and 64 per 1,000 never-married women among those with a bachelor's degree.

- Those with a master's degree or higher had an even higher rate of 78.4 first marriages per 1,000 never-married women.

- The first marriage rates were similar among women with less than a high school degree (29.0), a high school degree or GED (31.7), and some college education but no degree (32.6).

Figure 3. First Marriage Rate for Never-Married Women 18 and Older by Educational Attainment, 2019

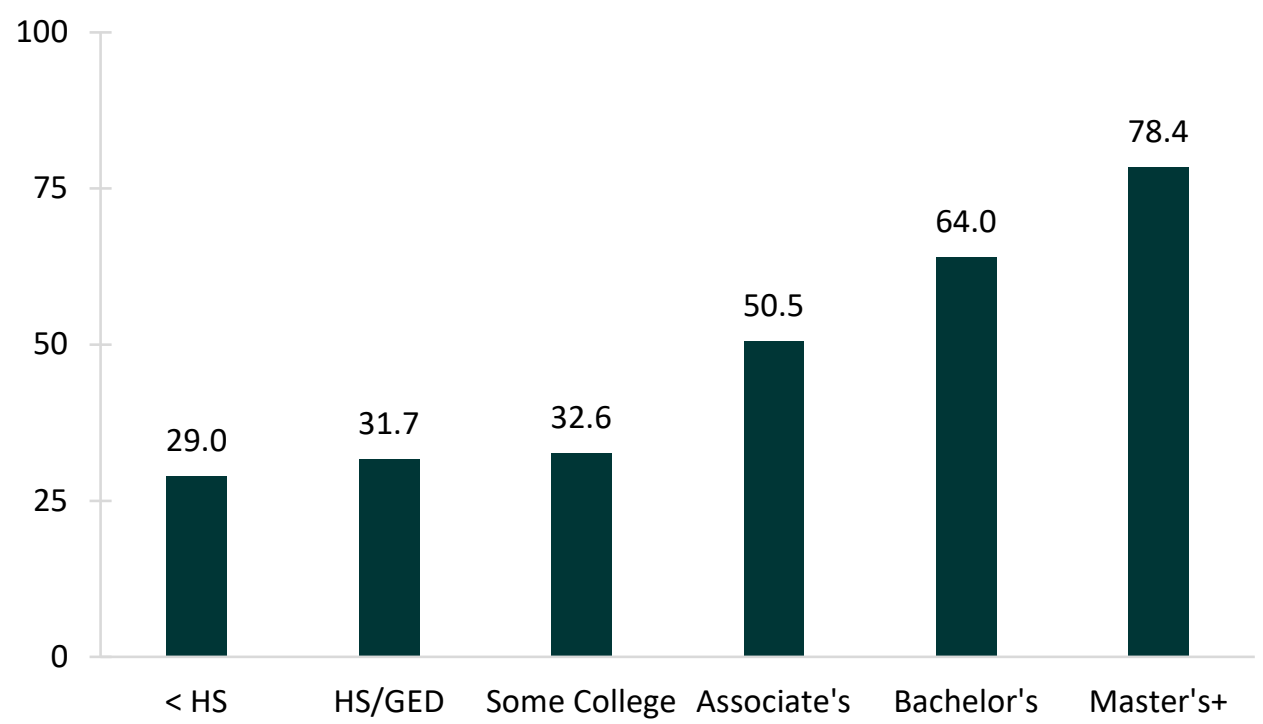

Source: NCFMR analyses of U.S. Census Bureau, American Community Survey, 1-yr. est., 2019

\section{References}

Allred, C. (2019). Marriage rate in the U.S.: Geographic variation, 2018. Family Profiles, FP-19-22. Bowling Green, OH: National Center for Family \& Marriage Research. https://doi.org/10.25035/ncfmr/fp-19-22

Anderson, L. R. (2016). First marriage rate in the U.S., 2014. Family Profiles, FP-16-18. Bowling Green, OH: National Center for Family \& Marriage Research. https://www.bgsu.edu/ncfmr/resources/data/family-profiles/anderson-first-marriage-rate-2014-fp-16-18.html

Manning, W. D. \& Payne, K. K. (2019). Marriage by the numbers. Family Profiles, FP-19-14. Bowling Green, OH: National Center for Family \& Marriage Research. https://doi.org/10.25035/ncfmr/fp-19-14

Payne, K. K. (2018). First marriage rate in the U.S., 2016. Family Profiles, FP-18-14. Bowling Green, OH: National Center for Family \& Marriage Research. https://doi.org/10.25035/ncfmr/fp-18-14

Payne, K. K. \& Gibbs, L. (2011). First marriage rate in the U.S., 2010. Family Profiles, FP-11-12. Bowling Green, OH: National Center for Family \& Marriage Research. http://www.bgsu.edu/content/dam/BGSU/college-of-arts-and-sciences/NCFMR/documents/FP/FP-11-12.pdf

Payne, K. K. (2010). Rate of first marriage in the U.S., 2008. Family Profiles, FP-10-05. Bowling Green, OH: National Center for Family \& Marriage Research. http://www.bgsu.edu/content/dam/BGSU/college-of-arts-and-sciences/NCFMR/documents/FP/Fp-10-05.pdf

Reynolds, L. (2020). Marriage rate in the U.S.: Geographic variation, 2019. Family Profiles, FP-20-24. Bowling Green, OH: National Center for Family \& Marriage Research. https://doi.org/10.25035/ncfmr/fp-20-24

Schweizer, V. (2020). First marriage rate in the U.S., 2018. Family Profiles, FP-20-01. Bowling Green, OH: National Center for Family \& Marriage Research. https://doi.org/10.25035/ncfmr/fp-20-01

Stykes, B., Payne, K. K., \& Gibbs, L. (2014). First marriage rate in the U.S., 2012. Family Profiles, FP-14-08. Bowling Green, OH: National Center for Family \& Marriage Research. http://www.bgsu.edu/content/dam/BGSU/college-of-arts-and-sciences/NCFMR/documents/FP/FP-14-08-marriage-rate2012.pdf

\section{Suggested Citation}

Reynolds, L. (2021). First marriage rate in the U.S., 2019. Family Profiles, FP-21-09. Bowling Green, OH: National Center for Family \& Marriage Research. https://doi.org/10.25035/ncfmr/fp-21-09

\section{BCSU. Family \& Marriage Research}

